\title{
Comparison analysis of Chinese and western leisure sports culture
}

\author{
Huiqiao Duan ${ }^{1,}$ a \\ ${ }^{1}$ Wuhan Business University, Wuhan, Hubei Province, China \\ a635102151@qq.com
}

Keywords: Sports culture, Chinese, western leisure sports, leisure sports

\begin{abstract}
Sports culture is present in all sports phenomenon and the sports life of a special cultural phenomenon, that is to say, people in the process of sports life and sports practice, for health of body and mind development, through the athletics, entertainment and educational means, such as changes in body shape and movement skills with movement attribute of culture. The Chinese sports culture is gestated in unique social environment and developed, thus forming formed closed, and restraint of Chinese sports culture. Is undoubtedly a conquest culture, western culture advocates continue to challenge the body's own, develop human potential, break through the human ability to the limit, thus formed the competition as the core of the western sports culture, this paper discusses the differences between Chinese and western leisure sports culture.
\end{abstract}

\section{Introduction}

China is a large country with a long history, is located in the east of Asia continent, the east is the ocean, northwest is mountains and desert, nearly 1000 square kilometers of territory to form a relatively closed environment, in such a relatively geographic environment formed an independent cultural system. Economic foundation of the generation and development of Chinese sports culture is a "Chinese" by agriculture agricultural economy, depreciation determines its core thought is emphasis on the harmony of man and nature, the pursuit of harmony, with the development of nature [1]. China's sports culture has deep roots, it is regional exchanges and integration. Traditional sports is given priority to with "health", so there are few violent ways of sports and often have their body movement is given priority to with internal, played down the body shape of exercise. Its purpose is to fitness, health, educational. Appropriate to Chinese ancient human movement, the quantity is not big nor small, exercise big will hurt the body, whereas small can't achieve the purpose of cultivate one's morality. It should also pay attention to these aspects in eating and sleeping. So the background of China's sports development is based on the background of Chinese culture.

\section{Differences between Chinese and western leisure sports culture}

The differences of Chinese and western sports culture in origin. We know that anything has its historical continuity, the development of the existing society is the continuation of social history. The existing culture is also in the history of the development of culture, any historical stages of human civilization is developed on the basis of the original civilization. The development of sports. Also must have formed in the long-term historical evolution of national style and national characteristics, it is the source of the sports culture, the formation of sports culture without the influence of historical tradition. In America, for example, American society without the history of the feudal society, no long-term feudal ideas and the formation of the traditional habit[1]. On the contrary, it is composed of immigrants from different cultural backgrounds. Because the traffic is relatively developed, alien invasion and migration is frequent, in its nearly two hundred years of development, outside the influence of western modern democracy, affected by the migration of national spirit, present a full of volatility and expansionary multicultural hybrid characteristics. So, in the not too long in the history of forming a good national tradition, this may be the reason it form the values today, the national spirit and historical origin of sport thoughts.

The differences of Chinese and western sports culture in the historical and cultural background. Sports culture has a very distinct history stages. Different stages of Chinese and 
western cultures show the characteristics of the image also shows the differences of the two. Originated from the Aegean sea waters of the ancient Rome and ancient Greek culture, the background is a competition between the tiny city-state, thus forming were jingling people attaches great importance to the physical strength, skill and so on when the idea of practical physical condition in the war. In China, due to the central plains region wide flat, jiangnan rich fish and rice, very suitable for agricultural development, formed the prosperous feudal dynasty and formed the Chinese nation "and" ideological core[2]. The border has minority, but most of the central plains of China is in a state of peace. People lack of competition environment, the differences of light weapons. So to form the harmonious health as the characteristics of sports culture in ancient China. With the rise of the United States. Especially they formed in the period of "wild, wild west" pioneer spirit, self-worth with great improvement of the western sports culture and an unprecedented development. After the founding of the people in China through the development of twists and turns, also on through continuous learning. Again using "sublation" attitude is the essence of the Renaissance of Chinese ancient culture. Formed its own unique sports culture.

Spirit essentially the difference between Chinese and western sports culture. Sports fitness value have been advanced by the world, but the influence of different cultural groups, they have different understanding of fitness function, in the western countries is very pay attention to sports for all parts of the body organs, the role of functional exercise, in the heat of the activities to achieve the purpose of promoting health. Influenced by traditional sports thought in our country, pay attention to retreat, formed a kind of attitude of indifference to sports fitness value[2]. When health needs, often cannot shift to the idea of sport as a leisure entertainment, the fitness function prominently displayed. The main factors causing the cultural differences between Chinese and western sports values, ways of thinking, moral sentiment, religion, national character, etc., these factors constitute the cultural organism, determines the development of the self culture type and dominant trend.

The differences of Chinese and western sports culture in the value choice. Western culture of the individual or the self is independent, expansion and externalization. In the concept of the west, only individual fully development to have the full development of the society. In the west to the individual personality as the main body of the social background, the social culture.

Chinese society of diversified values, such as the spring and autumn period and the warring states period of hundred schools of thought contend[1]. But after qin shi huang unified China, became a united empire thought characteristic, the author examines the oneness of values has become a symbol of Chinese unify. In two thousand years of feudal society, because of the feudal ruling class, the author examines the differences of light arms, has been inadequate attention to sports.

Different values of sports culture determines the clear difference between eastern and western sports culture values, also determines the different of the two kinds of sports culture development direction, and go deep into the core level of philosophy and values. Western sports culture concept of competition has become the mainstream of the modern world sports culture, the values of Chinese traditional sports culture, the implication of "nature and humanity" the pursuit of the all-round development of human beings, as well as the overall concept of human and the nature harmonious and unified thinking pattern and behavior way is bound to the values of the mainstream of western culture, well versed in, blending together to make due contribution to the development of the world sports culture.

The differences of Chinese and western sports culture in the way of thinking. The Chinese heavy intuitive insight, western abstract thought. For the above reasons, the west from the open ocean geographical environment, the developed commodity economy, broad democratic traditions etc. Deduce the representative of the western culture is progressive, individuality and openness, rheology characteristics of "culture" of competitive sports[3]. China's agriculture as the foundation, from closed self-sufficiency, the lack of higher cultural competition produces the advocation experience, pay attention to ethics, value etiquette cultivation, the farming culture with the characteristics of sound, also gives birth to the "health sports culture" the western way of thinking is rational theoretical and empirical analysis are closely linked, inseparable. 
In western philosopher's opinion, it is only speculative reason is the most real, the most perfect, the most beautiful and good, since the time of ancient Greece, the natural scientists and philosophers all the abstract logical thinking way as truth is the most basic means of knowing and grasping things, and the "analysis" or "logic" as all the tools of science[3]. Therefore, from sports in ancient Greece was born, the western sports culture has with demonstration and analysis of theoretical thinking. The ancient Olympic though is based on the basis of the ancient Greek gods worship and sacrifice, but the god of ancient Greek and unified, is god, the god of humanization, people in the worship of god at the same time pay more attention to in the transcendence of god, and pay attention to the strong physique, body strong and handsome, reflect people's creativity and initiative.

The differences of Chinese and western sports culture in the function structure. Western sports culture on the function structure is built on the basis of commercial, professional, the pursuit of faster, higher, stronger "extroversion" competitive way, rapid development speed, efficiency, more and more involved in economic and political factors, its trajectory is more and more with the intention of sports to keep fit. Therefore, the individual function and social function, internal function and external function show obvious tendency of separation [3]. Chinese sports culture as a kind of maintenance of the movement of life, retain more of the original color, health fitness, cultivate one's morality raises a gender, self-entertainment, entertaining function, remains its charm, its individual function and social function, internal function and external function is unified.

Western sports movement and muscle strong and handsome, athletic, pay attention to the shape of the praise to human body, emphasized the external body movement, all require large muscle groups involved in many activities way, and muscle motion. Advocate of human strength, speed, endurance, flexibility and other physical quality training. The function of each part of the exercise level, beautify the human body image, meet the spiritual sense of fulfillment. Western sports the pursuit of faster, higher, stronger, and the pursuit of confrontation and competition, the pursuit of superego. Beyond the natural value orientation is victory.

The differences of Chinese and western sports culture in the social moral. China's sports ethic culture ", "said things movement rules. "DE, too, have to also" is the right of things to deal with... . In China's traditional culture, people while learning "drive" and so on. But "to learn" mainly to learn about the ethics of knowledge, especially the Confucian ethics, after is respect for the "zero", the internalization of virtue. In this atmosphere can't produce the prototype of the competitive sports. Such as "national treasure" martial arts is the typical representative of the Chinese sports culture. "'" with performance is the traditional Chinese cultural characteristics. As li li-yan pointed out: China's traditional philosophy is the cornerstone of China's sports to a certain pattern.

Western sports ethics culture after Aristotle Epicurus school of thought: the whole philosophy is an orchard, logic is the fence, physics is the fruit trees, ethics is the fruit of fruit trees[4]. Hume thought: morality is the product of passion "3. Regardless of the Homer era hero of the corresponding social virtue, or Athens era of advocating sports spartans of virtue the pursuit of excellence, encourage people to make public their. The bible culture think: we are the lamb of god, we all are equal, we all have the right to the pursuit of interests. But everyone should accept limitations, this requires that the game has rules. This is also the reason of competitive sports was born in European culture.

The differences of Chinese and western sports culture in ideology. Chinese culture is developed on the basis of the feudal culture. Most people from perceptual experience, with intuitive grasp the real life experience and the overall image thinking and so on. This kind of values of science. In the eyes of the people gradually turned into an ingrained activity way[4]. This to a certain extent, affect and hinder the establishment and development of the contemporary sports spirit. Thus, with built in to decomposition, analysis as the main body of experimental science on the basis of modern western sport is completely different.

Western sports is based on the modern anatomy, physiology and other natural science developed. During the Renaissance, the western to decompose, the analysis method as the main body of experimental science, making the development of the sports have made a very good scientific basis. Is regarded as the cradle of western ancient culture, ancient Greek residing in Mediterranean countries, 
the geographic location of the openness and maritime trade way of life, has created many math and geometry talents[4]. They use math and geometry principle to explain human movement, created the sprint, long distance, high jump, discus with mathematical indicators to determine the sports performance. With the development of modern science, the empirical analysis and more development way of thinking, logical thinking and empirical analysis will become the main way of thinking for westerners.

The differences of Chinese and western sports culture in the different cultural background. Chinese traditional sports is based on agricultural civilization to patriarchal family as the background, with Confucianism as its core, formed the implicative, supine sports thought, it attaches importance to the harmony of man and nature, the pursuit of harmony, with the development of nature[4]. To survive in the competition, increase in competition, perfect, in competition to become people's common psychology, competition mechanism become the soul of western sports culture and core. On the concept of the project Settings also reflects the speed, height, physical characteristics such as far degree and weight and limit the potential for individuality, fully shows the movement of life ability, physiological limit the way of thinking of a challenge[4]. With the Chinese wushu's pursuit of balance and adapt to the natural spatial thinking the distinction that having essence.

\section{Summary}

By comparing Chinese and western sports culture, we can clearly found that the traditional Chinese sports culture with the advantages and disadvantages of international social environment under the premise, at the same time, we also see the development trend of western sports culture and the development of science and guidance. How to change our traditional sports idea, make the Chinese traditional sports culture to a more scientific and healthy development path, in line with international standards at the same time to carry forward our national traditional sports, is a primary issue in front of us, the development of Chinese sports culture is a basic goal, task and direction is to deepen understanding of sports culture connotation and re-examine sports culture of innovative thinking, establishment of sports culture fulcrum and end-result, effectively to reform Chinese traditional sports culture, make it more close to the trend of the development of the popularization, internationalization, along with the deepening of reform and opening up, gradually the Chinese sports culture into a new stage of development.

\section{References}

[1] Y.L. Liu and J.L. Zhong, Analysis of differences between the Chinese and western sports culture and its influence on the development of the sports, Sports Journal, 2013, pp.11-16.

[2] Y.L. Yang, The Comparison study between Chinese and western leisure sports culture, Sports teaching, 2014, vol.05, pp. 32-36.

[3] J.M, He and J.Hu, The difference between Chinese traditional sports culture and western culture contrast research of competitive sports, the modern education technology, 2008, vol.9, pp.15-20.

[4] G.F. Wang, The development of leisure sports culture in the western, Education theory research, 2012, vol.4, pp.42-47. 